University of Montana

ScholarWorks at University of Montana

Public and Community Health Sciences Faculty

Publications

Public and Community Health Sciences

$9-2012$

\title{
Asthma Randomized Trial of Indoor Wood Smoke (ARTIS): Rationale and Methods
}

Curtis W. Noonan

University of Montana - Missoula, curtis.noonan@mso.umt.edu

Tony Ward

University of Montana - Missoula, tony.ward@mso.umt.edu

Follow this and additional works at: https://scholarworks.umt.edu/pchs_pubs

Part of the Public Health Commons

Let us know how access to this document benefits you.

\section{Recommended Citation}

Noonan, Curtis W. and Ward, Tony, "Asthma Randomized Trial of Indoor Wood Smoke (ARTIS): Rationale and Methods" (2012). Public and Community Health Sciences Faculty Publications. 7.

https://scholarworks.umt.edu/pchs_pubs/7

This Article is brought to you for free and open access by the Public and Community Health Sciences at ScholarWorks at University of Montana. It has been accepted for inclusion in Public and Community Health Sciences Faculty Publications by an authorized administrator of ScholarWorks at University of Montana. For more information, please contact scholarworks@mso.umt.edu. 


\title{
Asthma randomized trial of indoor wood smoke (ARTIS): Rationale and Methods
}

\author{
Curtis W. Noonan ${ }^{*}$ and Tony J. Ward \\ Tony J. Ward: tony.ward@umontana.edu
}

\begin{abstract}
Background-Particulate matter (PM) exposures have been linked with poor respiratory health outcomes, especially among susceptible populations such as asthmatic children. Smoke from biomass combustion for residential home heating is an important source of PM in many rural or peri-urban areas in the United States.
\end{abstract}

\begin{abstract}
Aim-To assess the efficacy of residential interventions that reduce indoor PM exposure from wood stoves and to quantify the corresponding improvements in quality of life and health outcomes for asthmatic children.

Design-The Asthma Randomized Trial of Indoor wood Smoke (ARTIS) study is an in-home intervention study of susceptible children exposed to biomass combustion smoke. Children, ages 7 to 17, with persistent asthma and living in homes that heat with wood stoves were recruited for this three arm randomized placebo-controlled trial. Two household-level intervention strategies, wood stove replacement and air filters, were compared to a sham air filter placebo. Improvement in quality of life of asthmatic children was the primary outcomes. Secondary asthma-related health outcomes included peak expiratory flow (PEF) and forced expiratory volume in first second $\left(\mathrm{FEV}_{1}\right)$, biomarkers in exhaled breath condensate, and frequency of asthma symptoms, medication usage, and healthcare utilization. Exposure outcomes included indoor and outdoor $\mathrm{PM}_{2.5}$ mass, particle counts of several size fractions, and carbon monoxide.
\end{abstract}

Discussion-To our knowledge, this was the first randomized trial in the US to utilize interventions targeting residential wood stoves to assess the impact on indoor PM and health outcomes in a susceptible population.

Trial registration-ClincialTrials.gov NCT00807183.

\section{Keywords}

pediatric; asthma; home intervention; wood stove; filter; biomass combustion

\footnotetext{
(C) 2012 Elsevier Inc. All rights reserved.

"Corresponding author: Curtis W. Noonan, Ph.D., Center for Environmental Health Sciences, Department of Biomedical Sciences, 32 Campus Drive, The University of Montana, Missoula, MT 59812, curtis.noonan@umontana.edu, Phone: 406.243.4957, Fax: 406.243.2807.

COMPETING INTERESTS

The authors declare that they have no competing interests.

AUTHORS'CONTRIBUTIONS

CWN and TJW are the co-Principal Investigators and co-coordinators of the study. CWN and TJW drafted the manuscript, contributed to the study concept and design, revised the manuscript for important intellectual concept, and approved the final manuscript.

Publisher's Disclaimer: This is a PDF file of an unedited manuscript that has been accepted for publication. As a service to our customers we are providing this early version of the manuscript. The manuscript will undergo copyediting, typesetting, and review of the resulting proof before it is published in its final citable form. Please note that during the production process errors may be discovered which could affect the content, and all legal disclaimers that apply to the journal pertain.
} 


\section{Introduction}

Mortality and morbidity studies have demonstrated that PM is associated with adverse effects on respiratory health, particularly among susceptible populations such as asthmatics. Follow-up of cohorts or panels of asthmatic patients have demonstrated that increases in levels of $\mathrm{PM}_{10}$ and $\mathrm{PM}_{2.5}$ (PM less than 10 and $2.5 \mu \mathrm{m}$ in aerodynamic diameter, respectively) are associated with increases in severe asthma attacks, asthma symptoms, asthma medication usage, and hospital emergency department visits for asthma and upper respiratory infections [1-14]. PM exposures have been shown to result in annual lung function growth deficits that are greater than that attributed to passive smoke exposure in children [15].

Biomass combustion from residential heating devices can be a large contributor to ambient PM in rural communities. The Consumer Product Safety Commission estimates that there are 8.9 million wood stoves currently in use in the US [16]. The majority of these are old and inefficient, resulting in high levels of PM emissions [17]. In semi-urban to very rural environments, estimates of the wood smoke contribution to ambient particulate levels can range from $10 \%$ to $90 \%$ [18-20]. Wood stoves can also be significant sources of $\mathrm{PM}_{2.5}$ to the indoor environment. From an exposure and health point of view, this is important, as most people spend the majority of their time indoors, as much as $95 \%$ in some areas [21, 22].

Health agencies and clinical practitioners are increasingly interested in identifying costeffective interventions to improve quality of life among asthmatic children. In addition to improved clinical management, approaches may include strategies that reduce inhalation exposures to known asthma exacerbation triggers. Several studies have tested single [23-29] or multiple [30-33] home-based interventions to improve childhood asthma morbidity. To date all such randomized controlled trials in the United States have taken place in urban settings, and none of these studies specifically addressed in-home wood smoke-derived PM exposures. More recently, intervention trials in developing country settings have targeted indoor exposures due to biomass combustion cook stoves [34, 35]. However, the settings and exposure scenarios in developing countries are distinct from that of wood stove exposures in the United States or other developed countries. In addition, these cook stove intervention trials have focused on corresponding improvements in frequency of child respiratory infections rather than reductions in asthma morbidity.

In this paper, we present the project methodologies of the first randomized controlled trial to evaluate interventions targeting biomass smoke PM from older model (non-EPA certified, manufactured < 1995) residential wood stoves in homes of asthmatic children. This study took place in semi-urban to very rural areas of Montana, Idaho, and Alaska where residential wood combustion is the major source of $\mathrm{PM}_{2.5}$ and the primary source of home heating throughout the winter months.

\section{Methods}

\subsection{Study overview}

This was a three-arm randomized placebo-controlled intervention trial with two treatment arms, allowing for the assessment of both high and low cost strategies for reducing in-home wood smoke PM relative to a placebo. The intervention trial was targeted at asthmatic children living in non tobacco smoking homes that used older model wood stoves as the primary source of heating. Subjects were recruited as described below and randomized to one of three treatments: the placebo group receiving air filtration devices with a nonfunctioning filter (Tx1), the wood stove intervention group receiving newer, cleaner burning 
EPA-certified wood stoves (Tx2), and the air filter group receiving functioning air filtration devices (Tx3).

The exposure and health outcomes observations took place in each household on two occasions during each of the pre- and post-intervention winter periods. The four exposure sampling episodes included 48-hour continuous measurements of $\mathrm{PM}_{2.5}$ mass both inside and outside the homes. Other indoor measures included particle counts for several PM size fractions, carbon monoxide, temperature, and relative humidity. A one-week retrospective quality of life instrument, assessed twice during each winter period, was used as the primary health outcome variable. Self-collected pulmonary function measures were recorded twice daily for two, two-week periods each winter. Parents reported on asthma symptoms and asthma medication usage. During each 48-hour exposure sampling period at a given home, children collected exhaled breath condensate and spot urine samples on two consecutive mornings (Figure).

\subsection{Study locations}

The research proposed in this study was conducted in the northern Rocky Mountains (Montana and Idaho) and Alaska, where wood stove usage for residential home heating is prevalent. Specifically, intervention based studies were conducted in the following regions: 1) a 200-mile radius surrounding Missoula in western Montana; 2) the Nez Perce Indian Reservation in Idaho; and 3) Fairbanks, Alaska. These locations were chosen due to the existing local capabilities and established partnerships.

\subsection{Subject selection and eligibility criteria}

Our target sample size was 108 asthmatic children. We identified eligible asthmatic children and households through both active and passive procedures. Active recruitment was initiated through the administration of a brief student-based asthma and respiratory survey to $5^{\text {th }}$ through $11^{\text {th }}$ grade students. The survey, based on the International Study of Asthma and Allergy in Children (ISAAC) questionnaire, was validated for this age group [36]. A question on whether or not the child's residence contained a wood stove used for heating was included in the survey. Based on the results of these surveys, we generated a list of potentially eligible subjects reporting asthma symptoms and wood stove usage. Passive recruitment occurred when parents contacted personnel after learning about the study through posted flyers or notifications distributed through the schools.

The second step of the subject identification process was a telephone interview of a parent at potentially eligible households. Parents were asked to confirm whether or not their child currently had physician-diagnosed asthma. Parents also reported the approximate age of their wood stove and whether or not their wood stove was their primary source of heating. We also confirmed with the parent that there were no tobacco smokers in the household. If the child and the corresponding home was still eligible at this point we asked the parent several questions regarding the child's frequency of daytime symptoms, nighttime symptoms, and activity-limiting asthma exacerbations. Based on this initial assessment, eligible subjects included children, age 7 to 17 years, with mild to severe persistent asthma residing in a non tobacco smoking household that used an older model wood stoves as their primary source of heating. Upon completion of baseline measures during the preintervention winter, subjects were randomized into one of three treatment arms.

\subsection{Interventions}

Placebo Treatment, Inactive Air Filtration Units (Tx1)—Within each randomly assigned placebo home, two individual air filtration units with placebo filter material were utilized. A large $\left(20^{\prime} \times 18^{\prime}\right)$ Filtrete air filtration unit (Ultra Clean Air Purifiers, 3M, St. 
Paul, MN) with placebo filter was placed in the same room as the woodstove. Within the child's bedroom, a smaller Filtrete $\left(17^{\prime} \times 10^{\prime}\right)$ unit with placebo filter was installed. Both units were operated on the "high" setting throughout the duration of the winter, with filters changed out monthly. To assess compliance with continuous usage, each Filtrete unit was fitted with a data logging (voltage measuring) device which monitored on/off status. Upon completion of the study, placebo-assigned homes were provided with the appropriate filters to restore the air cleaning functionality of the unit.

Wood Stove Changeout Treatment (Tx2)_-Older model wood stoves were changed out and replaced with EPA-certified wood stoves. Note that alternatives such as pellet, natural gas, propane, etc. stoves were not provided as a changeout. The new stoves were all certified as low-emission according to EPA standards (produces only 2 to 5 grams of smoke per hour), and labeled by the Underwriters' Laboratories of Canada (ULC) or another testing and certification body for safety. EPA-certified wood stoves were purchased and installed by certified technicians within each community. In some cases, new hearth pads and venting packages were provided to the residences to meet code. Following installation, a contracted wood stove expert conducted specific training on best burn practices within the home, and verified the successful installation of the new stoves.

Air Filtration Unit Treatment (Tx3)-Filtrete Ultra Clean Air Purifiers (3M, St. Paul, MN) with active filters were utilized in the Tx3 arm. These devices have previously been shown to reduce indoor PM in wood stove homes [37]. Like Tx1, households randomized to the active filtration unit intervention were provided with two units - a larger one $\left(20^{\prime} \times 18^{\prime}\right)$ for the same room as the wood stove and a smaller one $\left(17^{\prime} \times 10^{\prime}\right)$ for the child's bedroom. Filters were changed out approximately once per month in an effort to maximize collection efficiency. Measures to assess and ensure compliance with continuous usage of the units were the same as described above for Tx1.

\subsection{Health outcomes}

The Pediatric Asthma Quality of Life Questionnaire (PAQLQ) is a 23-item asthma-specific battery which provides domain scores for symptoms (10 items), activity limitation (5 items), and emotional function (8 items) [38]. The score for each domain is the average of the items within it, with scores ranging from one to seven (with seven as the optimal score). Symptom and activity limitation subscales were reverse-scored. The total PAQLQ score was calculated as the mean score across the three domains. This questionnaire was directly administered to children twice per winter period.

Using the PiKo-1 meter (Ferraris), children performed a peak flow test two times daily (in the morning and in the evening) for a two week period following each 48-hour exposure sampling episode. The subject with parent supervision was trained to place the mouthpiece in their mouth and blow as hard as they could for several seconds. The child repeated this three times for each test, and the device stored the best result for both peak expiratory flow $(\mathrm{PEF})$ and exhaled volume in the first second $\left(\mathrm{FEV}_{1}\right)$. Outcomes from these measures included average morning $\mathrm{PEF}$ and $\mathrm{FEV}_{1}$, average evening $\mathrm{PEF}$ and $\mathrm{FEV}_{1}$, and $\mathrm{PEF}$ evening to morning variability. During the same two-week period, parents of participating children were asked to record health-related events for their child, including asthma symptoms during the day, night, and/or during exercise. The parent also reported on the child's acute usage of systemic corticosteroids and health care utilization, including unscheduled outpatient visits, emergency department visits, or hospitalizations. The twoweek peak flow measures and parent reporting of symptoms, medication usage and healthcare utilization was repeated twice during each winter period directly following the 48-hour exposure sampling events. 


\subsection{Biomarker Analysis}

Four exhaled breath condensate (EBC) samples per winter were collected using an Rtube breath condensate collector (Respiratory Research Inc., Charlottesville, VA). This device consists of a pre-cooled aluminum sleeve placed over the outside of a disposable vertical condensation/collection tube and connected to two-way non-rebreathing valve and mouthpiece. Subjects were instructed to breathe into the mouthpiece for 10-15 minutes on each morning of the two, 48-hour exposure sampling episodes per winter. EBC samples were aliquoted, stored in the field freezers, transported on dry ice to the laboratory, and stored at $-80^{\circ} \mathrm{C}$ for future analyses. Samples were analyzed for $\mathrm{pH}$ and 8 -isoprostane, a marker of oxidative stress. Concentrations of 8 -isoprostane were measured by specific enzyme immunoassay kits (Cayman Chemical, Ann Arbor, MI) [39, 40].

On the same schedule as EBC collection, children collected spot urine samples. Although an eligibility requirement was for subjects to live in non-smoking households, we analyzed subjects' urine samples for cotinine to characterize exposure to environmental tobacco smoke using a cotinine ELISA kit (CalBioTech, Spring Valley, CA). To account for urine dilution, urine samples were also analyzed for creatinine by ELISA (Cayman Chemical Company, Ann Arbor, MI). Standards and samples were analyzed in duplicate.

\subsection{Exposure assessment}

During each 48-hour sampling event per each of two winters, three air samplers were deployed within the home: 1) a DustTrak 8530 (TSI, Shoreview, MN) that continuously measured $\mathrm{PM}_{2.5}$ mass, 2) a Lighthouse 3016-IAQ particle counter (Lighthouse Worldwide Solutions, Fremont, CA) that continuously measured particle counts within five distinct size fractions $(0.3-10 \mu \mathrm{m}$ size range), and 3) a Q-Trak (TSI, Shoreview, MN) that continuously measured carbon monoxide, carbon dioxide, temperature and relative humidity. While sampling, these monitors were co-located and placed approximately 3-5 feet off of the ground within the same room as the wood stove. A second DustTrak (Model 8520 or 8530) was located outside the home within an enclosure, measuring ambient $\mathrm{PM}_{2.5}$ mass during the periods of interest. All samplers had 60-second recording intervals, and were zero calibrated prior to each sampling event. It is possible that the participant homes are located in proximity to other homes with wood stoves, and such sources of nearby PM could impact local exposures among participants. The co-localization of continuous ambient and indoor $\mathrm{PM}_{2.5}$ monitors at each participant residence will allow for a characterization of home infiltration rate and the distinction of indoor- versus outdoor-generated PM per previously published methods.[41, 42] These source calculations and infiltration rates will also be important in further describing exposure reduction effectiveness of the two strategies with one treatment arm (stoves) targeting the lower emissions from in-home wood burning and the other treatment arm (air filters) targeting indoor PM regardless of source.

Descriptive home characteristics data were captured from each residence, including size and age of home, presence of pets and secondary sources of heating. To complement the exposure sampling approach, a home activity record was used to identify any activities that may have generated elevated $\mathrm{PM}_{2.5}$ levels during each sampling event (cooking, cleaning, etc). A wood burn record was also used to determine frequency of wood burning, and dates/ times that the wood stove was loaded and stoked during each sampling event. Finally, a child in-home record was used to document the times the subject was actually within the home during the period of exposure assessment.

\subsection{Other measures}

Several additional measures were collected from children or their respective homes on only one occasion. Spirometry measures were collected from subjects using the EasyOne 
Frontline portable spirometer (ndd, Andover, MA) with disposable spirette breathing tubes. Subjects were asked to perform a forced vital capacity (FVC) maneuver, and two good maneuvers were required for a valid test. Spirometry outcomes included $\mathrm{FEV}_{1}$ percent of predicted (\%), $\mathrm{FVC} \%$ and $\mathrm{FEV}_{1} / \mathrm{FVC} \%$. Subject sensitivity to selected indoor allergens was assessed using a skin prick test (Multi Test II, Lincoln Diagnostics, Decatur, IL). Allergens tested included dust mite, dog, cat, cockroach, aspergillis and alternaria (ALK Abello, Round Rock, TX). Dust samples were collected in the homes at one time point to assess indoor allergen levels in settled dust using a Dustream collector system (Indoor Biotechnologies, Charlottesville, VA). Home visits for these measures were arranged by convenience and were not coordinated to correspond to the above-mentioned health on exposure assessment sampling visits. Archived meteorological data were also collected for the exposure sampling days at given homes from the nearest weather station.

\subsection{Planned analysis}

Statistical analyses will be conducted using SAS v9.2 (Cary, NC). Analyses will be performed according to intention to treat to include subjects that were randomized to treatment and have at least one baseline measure. The primary independent variable will be assignment to treatment arm. A descriptive analysis (e.g., frequencies, percents, and means) will be conducted to describe the groups with relation to the primary dependent variables and other pertinent demographic variables at baseline. T-tests, or $\chi^{2}$ tests as appropriate, will be used to compare differences between groups in descriptive characteristics such as age, number of other children in the home, sex, race/ethnicity, household income, allergen sensitivity, allergen levels in dust samples, medication use, and asthma severity.

The primary dependent variable for this trial is change in PAQLQ scores from preintervention winter to post-intervention winter. The two PAQLQ scores will be averaged within each winter period for each subject. The first crude analysis will utilize t-tests to assess differences (Tx2 versus $T \times 1$ and $T \times 3$ versus Tx 1 ) in total PAQLQ scores change, as well as change in the three subscale scores for PAQLQ. We will use linear mixed models with fixed effects for treatment group, random effects for repeated measures within subject and adjustment for across group baseline differences that may occur despite the randomization strategy. Because the analysis requires combining data that were collected in different communities over different time periods, we will also include community or cohort year as a factor in the linear mixed models. It is also possible that particular differences across community may be evident for only one of the three communities. Examples of such factors could be difference in ambient winter temperature between pre-intervention and post-intervention winters or difference in race/ethnicity composition. If so, these factors will be included in the models to determine if there are differential effects on change in PAQLQ scores according to these factors. Because we will be using intention to treat in our primary analysis, we will maintain subjects in the analysis when their urinary cotinine suggests passive or active exposure to tobacco smoke. Secondary analyses after excluding these subjects may be conducted if positive cotinine is an important variable in the multiple variable analyses. Other factors to be considered in secondary analyses will include baseline asthma severity, medication use and sensitivity to indoor allergens as potential effect modifiers.

The above-described exposure variables will also be used in an exposure response analysis of PAQLQ and other health outcomes. We will use linear mixed models to assess whether reductions in indoor $\mathrm{PM}_{2.5}$ or particle counts are associated with the asthma-related outcomes and biomarkers. Each exposure variable will be considered separately because changes in these measures will be highly collinear. 


\subsection{Expected results and power calculations}

Each treatment arm will be assessed for change in PAQLQ score from the pre-intervention winter period to the post-intervention winter period. When comparing two groups (e.g., Tx1 versus Tx2), a sample size of 30 subjects per group will provide $80 \%$ power to demonstrate a difference in scores of 1.00 units or greater at the $95 \%$ confidence level. This estimate was based on an independent t-test assuming a common standard deviation of 1.36 which was the baseline standard deviation of baseline PAQLQ measures in a prospective childhood asthma intervention study that, like our study, combined three different communities [43]. When evaluating within group changes, a sample size of 30 subjects per group would provide $80 \%$ power to demonstrate a difference in pre- versus post-intervention PAQLQ scores of 0.72 units. These estimates of inter-group and intra-group detectable differences are reasonable as a longitudinal study of indoor environmental interventions among asthmatic children in three communities demonstrated improvement of 1.32 units at 13 months of follow-up [33, 43]. For symptom reporting we will evaluate changes between preand post-intervention in days with asthma symptoms in a two week reporting period. We assumed a standard deviation of 2.52 based on a large-scale home intervention study evaluating the same outcome [30]. Our sample size of 30 subjects per intervention group would provide $80 \%$ power to detect a within-group change of 1.33 symptom days in a two week reporting period assuming a paired t-test with a $95 \%$ confidence interval. By comparison, home-based intervention studies among asthmatic children have yielded reductions in two-week symptom days ranging from 2.6 to 4.8 days in the intervention groups [30, 31]. For change in PEF variability (\%), we assumed a standard deviation of 16.74 based on a previous intervention trial of asthmatic children [30]. Our sample size of 30 subjects per intervention group would provide $80 \%$ power to detect a between-group difference of $8.9 \%$ PEF variability.

\section{Discussion}

Our study is currently evaluating the reduction in indoor PM following the described interventions and the corresponding impact on asthmatic children. These observations combined with a carefully designed exposure and health outcome assessment will allow us to characterize the wood smoke effects on respiratory health of children, and to evaluate clinically meaningful health improvements among asthmatic children. The use of the randomized trial design is atypical for environmental exposure research. Clearly, assigning subjects to a particular environmental agent suspected to cause adverse health consequences would be unethical. The study presented here describes a unique opportunity to evaluate environmental exposure-response relationships in wood stove homes using the randomized trial design. The intervention treatment is aimed at the household to reduce subject in-home exposures to PM. Other similar intervention studies have been conducted [23-35], but these have not specifically focused on wood stove interventions in homes with asthmatic children.

Importantly, our approach tested two distinct intervention strategies. The first strategy, the wood stove intervention arm, exclusively targeted wood combustion-derived PM. We have demonstrated previously that improved combustion efficiencies from new wood stoves can result in lower emissions [44-46]. Although our exposure assessment strategy was limited to particle phase contaminants, we anticipated that the wood stove intervention will also result in changes to gas phase emissions as noted in our prior studies [47, 48]. It is possible that exposure reductions in these wood stove intervention homes will be less than anticipated due to indoor infiltration of outdoor PM from other nearby sources or due to improper stove operation by the resident.

The second strategy, the air filter intervention arm, targeted indoor PM regardless of source. A key advantage of this intervention was that residents in this arm were blinded to 
intervention status with respect to the placebo arm (i.e., sham air filter). Comparing outcomes in the air filter versus the placebo group may be particularly important with respect to our subjective quality of life measures. Such reporting bias could be present in our wood stove intervention arm but will be minimized in our air filter versus placebo comparisons. One limitation of the air filter arm, however, is that other allergens (i.e. pollen and animal dander) may be reduced within the home in conjunction with wood smoke PM. These factors could potentially complicate the interpretation of our findings related to reduced asthma symptoms and reduced wood smoke concentrations within the residences.

Relatively few studies have been conducted in the United States to assess the health impacts of wood smoke from residential wood stove usage. Cross-sectional observational studies in the United States indicated higher frequency of symptoms that can be loosely described as asthma-related [49-51] and lung function decrement [52] among children living in wood stove homes compared to children living in homes without wood stoves. An ecological study examined respiratory symptoms in a wood stove community compared to a non-wood stove community [53]. Although there were no differences overall, there was a higher frequency of wheezing among children under five years old in the wood stove community, suggesting that young children may be susceptible to the adverse respiratory effects of wood smoke [53]. Studies of children living on the Navajo reservation in Arizona demonstrated greater risk of acute lower respiratory illness among children from households with wood stoves $[54,55]$. Two ecologic studies in areas where residential wood smoke accounted for $42 \%$ and $34 \%$ of PM showed associations between PM levels and hospital visits for asthma $[11,14]$. A recent ecological study was also conducted in a community that more closely approximates the exposure profile for northern Rocky Mountain wood smoke-impacted communities. In Christchurch, New Zealand approximately 90\% of PM was emitted from wood burners and open fires during winter. These investigators observed a greater than three-fold risk in total respiratory hospital admissions associated with PM [56]. More recently, a community-wide wood stove replacement program resulted in substantial reductions in ambient wintertime $\mathrm{PM}_{2.5}(27 \%)$ and corresponding reductions in the frequency of reported wheeze and respiratory infections among children $[57,58]$.

The epidemiological research described above has largely focused on ambient measures of wood smoke-derived PM and its association with respiratory effects. It is well understood that indoor exposures to pollutants and allergens are important determinants of asthma morbidity. Randomized trials of pharmacological treatment and case management strategies for mitigation of asthma morbidity are numerous, but in recent years many studies have also investigated the efficacy of home-based interventions to reduce important residential exposures among asthmatic children. The majority of studies have investigated a variety of interventions aimed at reducing allergen exposures in the home. Single intervention studies which have evaluated health outcomes resulting from strategies to mitigate dust mite, cockroach, mold, or pet allergen exposures have demonstrated positive, although not universal, benefits [23-29]. A multi-center randomized controlled trial of over 900 innercity asthmatic children with positive skin allergy tests assessed a high intensity multifaceted intervention which included education and environmental programs specific to the patient's allergy profile [30]. The intervention group in this study demonstrated reductions in asthma symptoms, asthma-related emergency health care visits, and school absences [30]. A smaller randomized controlled trial of inner-city children with a similar high intensity education and environmental intervention demonstrated reductions in asthma-related urgent health care visits and improvements in caregiver quality of life [31]. A third randomized controlled trial targeting inner-city asthmatic children found a significant improvement in daytime symptoms among children in homes receiving a multifaceted intervention targeting allergen and PM reduction [32]. Finally, a longitudinal study reporting pre- versus post-intervention measures demonstrated the effectiveness of a multifaceted intervention which included 
integrated pest management and education and support for asthma case management, yielding significant reductions in asthma symptoms and improvements in quality of life among the treated group $[33,43]$.

With few exceptions, the studies cited above, including the multifaceted interventions, do not directly target or assess in-home PM exposures. The multifaceted interventions included environmental tobacco smoke as a component to be addressed through a combination of education, behavioral alteration strategies, and environmental controls. Two randomized controlled trials have reported on the effectiveness of air filtration units in reducing in-home PM $[32,59]$. A small study reported a $73 \%$ reduction in total suspended particulates due to air filter usage and found modest improvements in total symptoms among the air filtration treatment group [59]. This trial contributed to a 2002 meta-analysis of air filtration unit studies which found significant improvements in total symptoms and sleep disturbance among asthmatics in homes in the air filtration treatment arm [29]. A second, more recent randomized controlled trial reporting on PM levels demonstrated a $39 \%$ reduction in $\mathrm{PM}_{10}$ among homes using air filtration units [32]. As described previously, this study found overall reductions in symptom reporting among the treatment group, but the multifaceted intervention which included behavioral and allergen-targeted environmental interventions makes it difficult to determine the main effect of PM reduction among this treatment group. Importantly, none of these intervention studies targeted homes at risk for non-tobacco related PM exposure such as homes using wood stoves as their primary heating source.

\section{Conclusion}

In many rural communities located in cold weather climates, use of a wood stove for residential home heating is common. Residential wood smoke is an important source of indoor PM, and this study has the potential to yield important information regarding the health of asthmatic children living in homes containing wood stoves and strategies for effective exposure reductions strategies. Intriguing parallels can be drawn between this study and current global efforts to reduce indoor biomass combustion exposures among children in developing countries $[34,35,60]$. In both developed and developing country settings, the introduction of improved stove technologies alone may not yield sufficient or consistent reductions in indoor biomass smoke exposures [34, 44-46]. A greater understanding of the behavioral, social, economic and technological aspects of these interventions may help to optimize exposure reductions and health improvements. In summary, this intervention trial will provide substantial power to assess health outcomes changes resulting from reductions in wood smoke exposures among asthmatic children, a population that is vulnerable to PM-related health effects. We will be able to evaluate clinically relevant outcomes of the planned intervention and ultimately to assess the efficacy of incorporating this intervention into future multifaceted public health strategies for susceptible children.

\section{Acknowledgments}

\section{AKNOWLEDGEMENTS AND FUNDING}

The study is funded by the National Institute of Environmental Health Sciences: 1R01ES016336-01 and 3R01ES016336-02S1. Additional support was provided by NCRR (COBRE P20RR017670). The authors thank John Balmes and Kirk Smith for their advice on study design. The authors also thank Lincoln Diagnostics and ALK Abello for the provision of allergen testing materials and 3M for advice and materials in the design of the placebo filter. 


\section{References}

1. Slaughter JC, Lumley T, Sheppard L, Koenig JQ, Shapiro GG. Effects of ambient air pollution on symptom severity and medication use in children with asthma. Ann Allergy Asthma Immunol. 2003; 91:346-53. [PubMed: 14582813]

2. Ostro B, Lipsett M, Mann J, Braxton-Owens H, White M. Air pollution and exacerbation of asthma in African-American children in Los Angeles. Epidemiology. 2001; 12:200-8. [PubMed: 11246581]

3. McConnell R, Berhane K, Gilliland F, Molitor J, Thomas D, Lurmann F, et al. Prospective Study of Air Pollution and Bronchitic Symptoms in Children with Asthma. Am J Respir Crit Care Med. 2003; 168:790-7. [PubMed: 12893648]

4. Yu O, Sheppard L, Lumley T, Koenig JQ, Shapiro GG. Effects of ambient air pollution on symptoms of asthma in Seattle-area children enrolled in the CAMP study. Environ Health Perspect. 2000; 108:1209-14. [PubMed: 11133403]

5. Wong TW, Lau TS, Yu TS, Neller A, Wong SL, Tam W, et al. Air pollution and hospital admissions for respiratory and cardiovascular diseases in Hong Kong. Occup Environ Med. 1999; 56:679-83. [PubMed: 10658547]

6. Thompson AJ, Shields MD, Patterson CC. Acute asthma exacerbations and air pollutants in children living in Belfast, Northern Ireland. Arch Environ Health. 2001; 56:234-41. [PubMed: 11480499]

7. Lin M, Chen Y, Burnett RT, Villeneuve PJ, Krewski D. The influence of ambient coarse particulate matter on asthma hospitalization in children: case-crossover and time-series analyses. Environ Health Perspect. 2002; 110:575-81. [PubMed: 12055048]

8. Jaffe DH, Singer ME, Rimm AA. Air pollution and emergency department visits for asthma among Ohio Medicaid recipients, 1991-1996. Environ Res. 2003; 91:21-8. [PubMed: 12550084]

9. Norris G, YoungPong SN, Koenig JQ, Larson TV, Sheppard L, Stout JW. An association between fine particles and asthma emergency department visits for children in Seattle. Environ Health Perspect. 1999; 107:489-93. [PubMed: 10339450]

10. Sheppard L, Levy D, Norris G, Larson TV, Koenig JQ. Effects of ambient air pollution on nonelderly asthma hospital admissions in Seattle, Washington, 1987-1994. Epidemiology. 1999; 10:23-30. [PubMed: 9888276]

11. Lipsett M, Hurley S, Ostro B. Air pollution and emergency room visits for asthma in Santa Clara County, California. Environ Health Perspect. 1997; 105:216-22. [PubMed: 9105797]

12. English PB, Von Behren J, Harnly M, Neutra RR. Childhood asthma along the United States/ Mexico border: hospitalizations and air quality in two California counties. Rev Panam Salud Publica. 1998; 3:392-9. [PubMed: 9734219]

13. Peel JL, Tolbert PE, Klein M, Metzger KB, Flanders WD, Todd K, et al. Ambient air pollution and respiratory emergency department visits. Epidemiology. 2005; 16:164-74. [PubMed: 15703530]

14. Schwartz J, Slater D, Larson TV, Pierson WE, Koenig JQ. Particulate air pollution and hospital emergency room visits for asthma in Seattle. Am Rev Respir Dis. 1993; 147:826-31. [PubMed: 8466116]

15. Gauderman WJ, McConnell R, Gilliland F, London S, Thomas D, Avol E, et al. Association between air pollution and lung function growth in southern California children. Am J Respir Crit Care Med. 2000; 162:1383-90. [PubMed: 11029349]

16. Zamula, WW. Room heating equipment exposure survey. Washington, D.C: U.S. Consumer Product Safety Commission, Directorate for Economic Analysis; 1989.

17. Air Quality Management Work Group. Recommendations to the Clean Air Act Advisory Committee: Phase I and Next Steps. Washington, D.C: 2005.

18. Naeher LP, Brauer M, Lipsett M, Zelikoff JT, Simpson CD, Koenig JQ, et al. Woodsmoke health effects: a review. Inhal Toxicol. 2007; 19:67-106. [PubMed: 17127644]

19. Ward TJ, Rinehart L, Lange T. The 2003/2004 Libby, Montana PM2.5 Source Apportionment Research Study. Aerosol Sci Tech. 2006; 40:166-77.

20. Ward T, Lange T. The impact of wood smoke on ambient PM2.5 in northern Rocky Mountain valley communities. Environ Pollut. 2010; 158:723-9. [PubMed: 19897293] 
21. Fishbein L, Henry C. Introduction: workshop on the methodology for assessing health risks from complex mixtures in indoor air. Environ Health Perspect. 1991; 95:3-5.

22. Jenkins P, Phillips T, Mulberg J, Hui S. Activity patterns of Californians: use of and proximity to indoor pollutant sources. Atmospheric Research. 1992; 26A:2141-8.

23. Gotzsche, PC.; Johansen, HK.; Schmidt, LM.; Burr, ML. Cochrane Database Syst Rev. 2004. House dust mite control measures for asthma; p. CD001187

24. Gergen PJ, Mortimer KM, Eggleston PA, Rosenstreich D, Mitchell H, Ownby D, et al. Results of the National Cooperative Inner-City Asthma Study (NCICAS) environmental intervention to reduce cockroach allergen exposure in inner-city homes. J Allergy Clin Immunol. 1999; 103:5016. [PubMed: 10069886]

25. Carter MC, Perzanowski MS, Raymond A, Platts-Mills TA. Home intervention in the treatment of asthma among inner-city children. J Allergy Clin Immunol. 2001; 108:732-7. [PubMed: 11692097]

26. Eggleston PA, Wood RA, Rand C, Nixon WJ, Chen PH, Lukk P. Removal of cockroach allergen from inner-city homes. J Allergy Clin Immunol. 1999; 104:842-6. [PubMed: 10518830]

27. Kercsmar CM, Dearborn DG, Schluchter M, Xue L, Kirchner HL, Sobolewski J, et al. Reduction in asthma morbidity in children as a result of home remediation aimed at moisture sources. Environ Health Perspect. 2006; 114:1574-80. [PubMed: 17035145]

28. Bernstein JA, Bobbitt RC, Levin L, Floyd R, Crandall MS, Shalwitz RA, et al. Health effects of ultraviolet irradiation in asthmatic children's homes. J Asthma. 2006; 43:255-62. [PubMed: 16809237]

29. McDonald E, Cook D, Newman T, Griffith L, Cox G, Guyatt G. Effect of air filtration systems on asthma: a systematic review of randomized trials. Chest. 2002; 122:1535-42. [PubMed: 12426250]

30. Morgan WJ, Crain EF, Gruchalla RS, O’Connor GT, Kattan M, Evans R 3rd, et al. Results of a home-based environmental intervention among urban children with asthma. N Engl J Med. 2004; 351:1068-80. [PubMed: 15356304]

31. Krieger JW, Takaro TK, Song L, Weaver M. The Seattle-King County Healthy Homes Project: a randomized, controlled trial of a community health worker intervention to decrease exposure to indoor asthma triggers. Am J Public Health. 2005; 95:652-9. [PubMed: 15798126]

32. Eggleston PA, Butz A, Rand C, Curtin-Brosnan J, Kanchanaraksa S, Swartz L, et al. Home environmental intervention in inner-city asthma: a randomized controlled clinical trial. Ann Allergy Asthma Immunol. 2005; 95:518-24. [PubMed: 16400889]

33. Levy JI, Brugge D, Peters JL, Clougherty JE, Saddler SS. A community-based participatory research study of multifaceted in-home environmental interventions for pediatric asthmatics in public housing. Soc Sci Med. 2006; 63:2191-203. [PubMed: 16781807]

34. Smith KR, McCracken JP, Weber MW, Hubbard A, Jenny A, Thompson LM, et al. Effect of reduction in household air pollution on childhood pneumonia in Guatemala (RESPIRE): a randomised controlled trial. Lancet. 2011; 378:1717-26. [PubMed: 22078686]

35. Selak V, Elley CR, Crengle S, Harwood M, Doughty R, Arroll B, et al. IMProving Adherence using Combination Therapy (IMPACT): design and protocol of a randomised controlled trial in primary care. Contemp Clin Trials. 2011; 32:909-15. [PubMed: 21777702]

36. Magzamen S, Mortimer KM, Davis A, Tager IB. School-based asthma surveillance: a comparison of student and parental report. Pediatr Allergy Immunol. 2005; 16:669-78. [PubMed: 16343089]

37. Hart JF, Ward TJ, Spear TM, Rossi RJ, Holland NN, Loushin BG. Evaluating the effectiveness of a commercial portable air purifier in homes with wood burning stoves: a preliminary study. $\mathrm{J}$ Environ Public Health. 2011; 2011:324809. [PubMed: 21331283]

38. Juniper EF, Guyatt GH, Feeny DH, Ferrie PJ, Griffith LE, Townsend M. Measuring quality of life in children with asthma. Qual Life Res. 1996; 5:35-46. [PubMed: 8901365]

39. Baraldi E, Ghiro L, Piovan V, Carraro S, Ciabattoni G, Barnes PJ, et al. Increased exhaled 8isoprostane in childhood asthma. Chest. 2003; 124:25-31. [PubMed: 12853498]

40. Zanconato S, Carraro S, Corradi M, Alinovi R, Pasquale MF, Piacentini G, et al. Leukotrienes and 8 -isoprostane in exhaled breath condensate of children with stable and unstable asthma. J Allergy Clin Immunol. 2004; 113:257-63. [PubMed: 14767439] 
41. Allen R, Larson T, Sheppard L, Wallace L, Liu LJ. Use of real-time light scattering data to estimate the contribution of infiltrated and indoor-generated particles to indoor air. Environ Sci Technol. 2003; 37:3484-92. [PubMed: 12953856]

42. Barn P, Larson T, Noullett M, Kennedy S, Copes R, Brauer M. Infiltration of forest fire and residential wood smoke: an evaluation of air cleaner effectiveness. J Expo Sci Environ Epidemiol. 2008; 18:503-11. [PubMed: 18059421]

43. Clougherty JE, Levy JI, Hynes HP, Spengler JD. A longitudinal analysis of the efficacy of environmental interventions on asthma-related quality of life and symptoms among children in urban public housing. J Asthma. 2006; 43:335-43. [PubMed: 16801137]

44. Noonan C, Navidi W, Sheppard L, Palmer C, Bergauff M, Hooper K, et al. Residential indoor PM2.5 in wood stove homes: follow-up of the Libby changeout program. Indoor Air. 2012 In Press.

45. Ward T, Boulafentis J, Simpson J, Hester C, Moliga T, Warden K, et al. Lessons learned from a woodstove changeout on the Nez Perce Reservation. Sci Total Environ. 2011; 409:664-70. [PubMed: 21144555]

46. Ward TJ, Palmer C, Bergauff M, Hooper K, Noonan CW. Results of a residential indoor PM2.5 sampling program before and after a woodstove changeout. Indoor Air. 2008; 18:408-15. [PubMed: 18665872]

47. Bergauff M, Ward T, Noonan C, Palmer C. The effect of a woodstove changeout on ambient levels of PM2.5 and chemical tracers for woodsmoke in Libby, Montana. Atmospheric Environment. 2009 In Press.

48. Ward TJ, Palmer CP, Houck JE, Navidi WC, Geinitz S, Noonan CW. Community woodstove changeout and impact on ambient concentrations of polycyclic aromatic hydrocarbons and phenolics. Environ Sci Technol. 2009; 43:5345-50. [PubMed: 19708364]

49. Honicky RE, Osborne JS 3rd, Akpom CA. Symptoms of respiratory illness in young children and the use of wood-burning stoves for indoor heating. Pediatrics. 1985; 75:587-93. [PubMed: 3975129]

50. Butterfield P, LaCava G, Edmundson E, Penner J. Woodstoves and indoor air: The effects on preschoolers' upper respiratory systems. Journal of Environmental Health. 1989; 52:172-3.

51. Noonan CW, Ward TJ. Environmental tobacco smoke, woodstove heating and risk of asthma symptoms. J Asthma. 2007; 44:735-8. [PubMed: 17994403]

52. Johnson K, Gideon R, Loftsgaarden D. Montana Air Pollution Study: Children's health effects. Journal of Official Statistics. 1990; 5:391-408.

53. Browning K, Koenig J, Checkoway H, Larson T, Pierson W. A questionnaire study of respiratory health in areas of high and low ambient wood smoke pollution. Pediatric Asthma Allergy and Immunology. 1990; 4:183-91.

54. Robin LF, Less PS, Winget M, Steinhoff M, Moulton LH, Santosham M, et al. Wood-burning stoves and lower respiratory illnesses in Navajo children. Pediatr Infect Dis J. 1996; 15:859-65. [PubMed: 8895916]

55. Morris K, Morgenlander M, Coulehan JL, Gahagen S, Arena VC. Wood-burning stoves and lower respiratory tract infection in American Indian children. Am J Dis Child. 1990; 144:105-8. [PubMed: 2294707]

56. McGowan JA, Hider RN, Chacko E, Town GI. Particulate air pollution and hospital admissions in Christchurch, New Zealand. Aust N Z J Public Health. 2002; 26:23-9. [PubMed: 11895020]

57. Ward TJ, Palmer CP, Noonan CW. Fine particulate matter source apportionment following a large woodstove changeout program in Libby, Montana. J Air Waste Manag Assoc. 2010; 60:688-93. [PubMed: 20564994]

58. Noonan CW, Ward TJ, Navidi W, Sheppard L. A rural community intervention targeting biomass combustion sources: effects on air quality and reporting of children's respiratory outcomes. Occup Environ Med. 2012; 69:354-60. [PubMed: 22302628]

59. Reisman RE, Mauriello PM, Davis GB, Georgitis JW, DeMasi JM. A double-blind study of the effectiveness of a high-efficiency particulate air (HEPA) filter in the treatment of patients with perennial allergic rhinitis and asthma. J Allergy Clin Immunol. 1990; 85:1050-7. [PubMed: 2191991] 
60. The World Bank. Household Cookstoves, Environment, Health, and Climate Change: A New Look at an Old Problem. Washington, DC: 2011. 


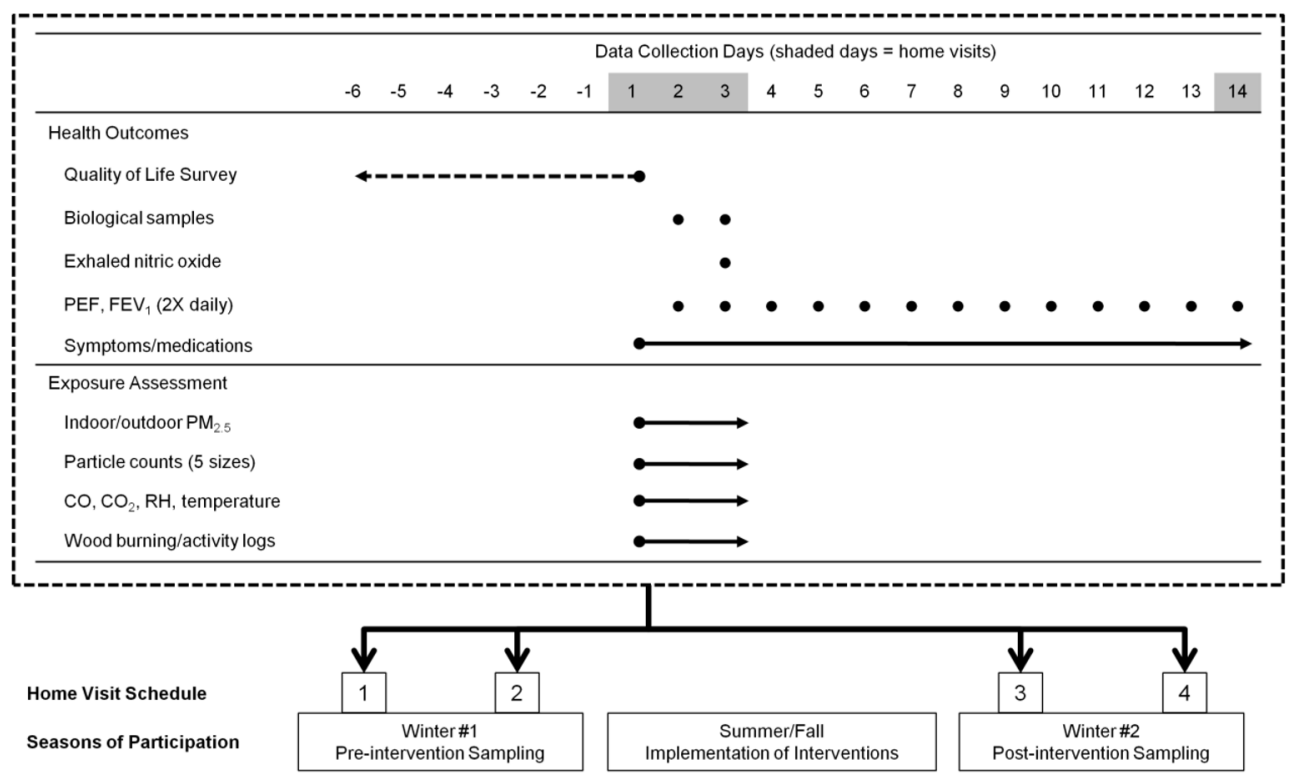

Figure 1.

Data collection strategy. Four sampling episodes occur at each participant home. Two sampling episodes occur during the pre-intervention winter, and two sampling episodes occur during the post-intervention winter. The implementation of household interventions (i.e., air filter, new wood stove, or placebo filter) occurs during the summer or fall between the two winters. Each sampling episode, illustrated in the table surrounded by the dashed line box, includes data collection for both health outcomes and exposure assessment. The dashed arrow for the pediatric asthma quality of life survey indicates that the data reflect the child's symptoms, limitations and other quality of life indicators during the week prior to the corresponding home visit. Solid lines indicate periods during which data are collected on a continuous basis. Solid dots indicate measures that are assessed at specific time points (e.g., mornings for biological sample collections or mornings and evenings for pulmonary function measures). 